\title{
AIR POLLUTION CONTROL TECHNOLOGY: RESEARCH AND DEVELOPMENT ON NEW AND IMPROVED SYSTEMS
}

\author{
JOHN H. LUDWIG*
}

\section{INTRODUCTION}

It is one of the great ironies of the twentieth century that we should be threatened by a cloud of pollution created by our own technological progress-and we are challenged to use our ingenuity to eliminate the production of pollutants that destroy property, damage plant life, endanger human health, and rob us of our enjoyment of natural beauty in our urban areas. Unfortunately, the job of control is not an easy one. There are as many potential sources of air pollution as there are manufacturing operations, motor vehicles, home heaters, power plants, and incinerators, to list some of the major sources.

Every year the number of possible sources increases sharply with the accelerating trends of population growth, urbanization, industrialization, increased affuence, and greater mobility. It has been estimated that total passenger car registration will reach I20 million by 1985 . There were 75 million cars in 1965 . And in 1985 there will be another 20 million trucks and buses.

In the decade between 1966 and 1976 it has been estimated that emissions of sulfur dioxide from combustion and industrial processes will increase from about 23 million tons per year to about 40 million tons per year even though a severe but realistic control program is effected. The volume of solid wastes will increase from 170 million to 230 million tons per year during this same decade, and most importantly, the percentage of these wastes that will have to be incinerated will increase at a much greater rate as the space available for landfill becomes even more scarce.

Just to maintain present air quality we will have to make great progress in pollution control; to effectively clean up the air will require increased application of control procedures already available as well as adoption of new techniques, which are only now under development, as soon as these are reduced to reasonable practice.

The need for a vigorous control program has been recognized by President Johnson $^{1}$ and by the Congress ${ }^{2}$ and is reflected in the Air Quality Act of $1967,{ }^{3}$ which goes far beyond previous legislation in providing the administrative procedures and

- B.S. 1934, University of California (Berkeley); M.S. r94I, University of Colorado; M.S. 1956, Sc.D. 1958, Harvard University. Associate Director, National Center for Air Pollution Control, U.S. Public Health Service, Department of Health, Education, and Welfare.

${ }^{2}$ E.g., President of the Untred States, Message on Atr Pollution, H.R. Doc. No. 47, 9oth Cong., Ist Sess. (I967).

'E.g., H.R. REP. No. 728, goth Cong., Ist Sess. (1967); S. ReP. No. 403, 90th Cong., Ist Sess. (1967); H.R. Rep. No. 916, goth Cong., Ist Sess. (1967) (conference report).

38 I Stat. 485 , amending 42 U.S.C. $\$ 9857$ to I857l (rg64). 
financial backing for an effective program. One of the requirements of this act is that the Department of Health, Education, and Welfare develop and publish information on techniques for preventing and controlling air pollution, including costeffectiveness of alternative methods. ${ }^{4}$ Reports on control of specific pollutants are to be published concurrently with the Department's air quality criteria describing the effect of these pollutants on people and on property. ${ }^{5}$ The first reports on sulfur oxides and particulates are expected to be published during the latter part of Ig68, and will be followed by reports on carbon monoxide and other pollutants.

The Air Quality Act also provides for a substantially accelerated research effortan effort which for the first time is commensurate with the magnitude of the air pollution control problem. ${ }^{6}$ Special emphasis is being placed on finding new and improved ways of dealing with the complex problems associated with combustion of fuels, especially those fuels containing a high percentage of sulfur and those used in motor vehicles. ${ }^{7}$

In response to the need to develop new and more efficient methods for combatting pollution from a multitude of sources, the National Center for Air Pollution Control has expanded research and development in its own facilities and in those of other federal departments and agencies. But more significantly, the Center will utilize the technological resources of the entire nation. Private industry is especially capable of contributing to the search for practical solutions to the various technical problems involved in controlling air pollution; the federal program is already moving in this direction. The language of the Air Quality Act clearly reveals the intent of Congress that there shall be the closest kind of cooperation, not only between the Center and state, municipal, and county governments in control programs for enforcing regulations on pollution control, but also between the federal government and all segments of the private sector to assist, both technically and financially, in the development of new or improved technology. ${ }^{8}$

In some areas of control technology we have begun to make considerable progress, but there is much yet to be done. In this article I shall attempt to indicate the present status of control technology and the direction of future research and development.

\section{The Control of Pollution from Stationary Sources}

If smoke from many factory stacks is no longer black, this is due to the application of technology that has been available for some time-at some economic penalty, of course-for the removal of particulates from flue gas wastes. Many factories use electrostatic precipitators which trap particles by applying electrical charges to them.

\footnotetext{
is roj(c), 8x Stat. 49I (1967).

\$ ฐ ro7(b), 8I Stat. 49I (1967); see H.R. Rep. No. 728, goth Cong., xst Sess. 15-IÉ, 33-34 (1967).

- ई ro3, 8r Stat. 486 (1967).

'T I04, 8I Stat. 487 (1967).

${ }^{8}$ E.g., \$ ro2, 81 Stat. $485(1967)$.
} 
Others use scrubbers in which process exhausts are forced through a liquid spray, and still others employ filters of various types, or devices that utilize inertial properties of the particles for collection.

Particulate control, however, is not so complete or so economical as it needs to be to meet the need for removal of ever-increasing percentages of material from process effluents. Very small particles elude most equipment designed to control air pollution, and it is this portion of particulate pollution which remains suspended indefinitely in the atmosphere and which produces the greatest potential hazard to human health, or, for that matter, threatens to have long term effects on the earth's climate. Small particles can penetrate more deeply into the respiratory system, carrying on their surfaces traces of many chemicals. Such particles, when added to the atmosphere in increasing amounts, can result in a decrease in the earth's albedo and a cooling of the atmosphere.

Although private industry is responsible for the development of most of the control technology currently available for particulates, the National Center for Air Pollution Control (NCAPC) in the last several years has conducted research in its own laboratories to develop improved fabric filters (baghouses) capable of trapping tiny particles. The NCAPC has been experimenting with fabrics which can withstand the corrosive effects of gases at elevated temperatures, and with improved techniques for removing the accumulation of particulates on the filter bags.

At the present time, a major effort nationally is focused on the control of sulfur oxides from stationary sources by both private industry and the federal governmentespecially by the Government. Sulfur oxide pollution is largely created by the combustion of coal and fuel oils used in heating and in generation of power. The Air Quality Act of 1967 specifically authorizes appropriations of up to $\$ 35$ million for fiscal year 1968 and $\$ 90$ million for fiscal year $1969^{\circ}$ for development of methods "having industry-wide application, for the prevention and control of air pollution resulting from combustion of fuels"; ${ }^{10}$ and so work is being rapidly accelerated on control of pollution emissions resulting from the use of fossil fuels in both vehicular and stationary sources.

A segment of the sulfur oxide control research is directed towards finding ways to remove sulfur from coal and heavy fuel oils before they are shipped to users, other research is aimed at developing processes for removing sulfur by the addition of sorbent materials to the combustion process itself, and still other research involves the removal of sulfur oxides from flue gases before they leave the smoke stacks.

The National Center for Air Pollution Control has supported studies at the Commercial Testing and Engineering Company of Chicago, the U.S. Bureau of Mines, and the Illinois Geological Survey to evaluate the cleanability of various coals produced in the United States; work is still underway by these groups. A coopera-

if 104 (c), 8I Stat. 488 (1967).

${ }^{10}$ g $_{104}(\mathrm{a}), 8 \mathrm{I}$ Stat. 487 (1967). 
tive study by Bituminous Coal Research, Inc, has also been funded to investigate the removal of pyrite sulfur particles from fine coals. A pilot-scale facility for evaluating the efficiency of commercial methods for pyrite separation and concentration has been operating since February 1968.

Studies by Arthur D. Little, Dorr-Oliver, and Bechtel are currently being conducted under NCAPC sponorship to determine the technical feasibility and economics of proved commercial processes capable of converting pyrite-coal refuse material into valuable byproducts.

The petroleum industry has been in the forefront in the development of methods for the desulfurization of high-sulfur residual fuel oils, and presently there are under construction a number of refineries using proprietary processes.

The NCAPC has been supporting a major program to remove sulfur during the combustion process itself which may be especially useful for the control of sulfur oxide pollution from power plants. Industry also has been active in this area, and one industrial concern markets equipment effective in removal of sulfur oxides during combustion. One process under extensive development by private and public efforts involves injecting ground limestone or dolomite sorbent materials into a furnace during firing. Sulfur oxide pollutants are collected on the surfaces of the sorbent particles and are thus removed from flue gases by collecting the particles together with the flyash in a dry or wet-type collecting device. Studies are underway for the utilization of the collected flyash-reacted limestone mixture to produce a useful byproduct such as brick or building block. To advance this process the NCAPC is supporting at several laboratories an intensive program for testing samples of limestone and dolomite obtained from quarries around the country. It is important that many sorbents be evaluated to determine the optimum properties, both chemical and physical, for use by power plants in different parts of the United States. This program is a cooperative one involving studies also supported by the coal and electric utilities industries.

The design of a prototype dry injection process to be installed on two TVA power plants has been started. These units are scheduled to begin operation in mid-1969 and will be operated under a comprehensive test program for approximately eighteen months.

To generate additional fundamental data needed to improve the application of the limestone process, five fundamental and applied research contracts were negotiated during 1967. These are two industrial contracts with Babcock and Wilcox and with Esso Research and Engineering to study process kinetics and to screen limestone reactants; a contract with West Virginia University's Coal Research Bureau to explore the potential of using limestone-modified flyash; a contract with Battelle Memorial Institute to investigate reaction and process kinetics of the limestonesulfur dioxide reaction; and support to the Tennessee Valley Authority to investigate 
the effect of physical properties of limestone and for conceptual design studies of limestone processes.

A process that involves the treatment of flue gases-the one that has been most extensively developed for American application-involves the use of alkalized alumina absorbent. Work conducted since 1957 by the Bureau of Mines for the NCAPC indicates that alkalized alumina is a promising sulfur oxide sorbent that can be regenerated to yield a sulfur-rich gas which can be converted to elemental sulfur. The Bureau of Mines has under test a semi-pilot plant to develop information required for pilot plant trials. The Central Electricity Generating Board (CEGB) has also developed data for pilot application in England. In the last year NCAPC has stepped up its activities, heading towards early pilot plant trials in the United States. A high degree of cooperative exchange has been maintained between the CEGB and the NCAPC; and the National Center and the Electric Research Council in the United States are now negotiating with the British for joint support of their large prototype plant study. If an agreement can be reached, a saving of a year's time will be realized in the pilot demonstration in the United States.

An adjunct process being studied for removing sulfur oxides from flue gases after injection of powdered limestone or dolomite sorbents into the furnace involves the use of wet scrubbers before discharge out the stack. This process is now under engineering design for application to two power plants in the Midwest. For further improvement of this system contract studies are underway for prototype-scale limestone scrubber systems investigating the process kinetics of several scrubber types and defining and solving known engineering problems related to wet scrubbing of flue gas. These problems include corrosion and scaling, plume reheating (the flue gas must be reheated so that it will rise through the stack and will disperse high in the air instead of settling immediately to the ground), potential water pollution, and solid disposal.

To develop improved new processes for the control of sulfur oxides from fuel combustion, the NCAPC has under study by contract bench-scale studies involving a large number of new processes. These methods, termed second generation processes, are expected to be more economical and efficient than the first generation processes now under development for pilot scale trials.

Although the percentage of total sulfur oxide emissions from processes other than the combustion of fossil fuels is a relatively small proportion of the total burden of sulfur pollution, individual industrial plants may often become local problems, creating an unattractive, unpleasant, and sometimes unhealthy environment for the communities in which they exist. The National Center is, therefore, now in the process of planning a series of cooperative studies with industry to encourage more extensive control of sources such as primary smelters, pulp and paper mills, sulfuric acid plants, and coke plants. These studies will pinpoint many research and development needs. 
In the immediate future the National Center for Air Pollution Control will expand research on pollutants from stationary sources other than particulates and sulfur oxides. An accelerated program involving control of nitrogen oxides is already being launched with a comprehensive systems engineering study which will evaluate the nitrogen oxides control problem in terms of the type, number, magnitude, and location of stationary sources of the pollutant now and through the year 2000, and the economics associated with control of these sources. From this systems study, a detailed plan will be formulated for a research and development program to make technology available for control of nitrogen oxides.

To date, most of the work on nitrogen oxide control from stationary sources has been conducted by industry and has involved combustion process modifications. Babcock and Wilcox, for instance, has developed two-stage combustion as a means of partial control for some designs of oil and gas-fired boilers. Combustion Engineering has done enough work to show that boiler design can affect the formation of nitrogen oxides. Esso Research and Engineering has also shown in the laboratory that nitrogen oxide emissions from oil-fired units can be reduced by changing fuel ratios.

Several organizations, including the Franklin Institute, Illinois Institute of Technology, University of California, and Chevron Research, have investigated catalytic decomposition as a possible approach to nitrogen oxides control; but most of these studies have been oriented towards application to the control of emissions from automobiles.

Current NCAPC projects on residential furnaces are giving first consideration to nitrogen oxides. A study supported by the National Center for Air Pollution Control at the U.S. Bureau of Mines is aimed at determining fundamental kinetic data on the formation of nitrogen oxides in gas flames.

As far as is possible, new and improved sulfur oxides control processes, such as the molten carbonate process (one of the second generation processes under consideration), will be evaluated for their nitrogen oxides control potential.

In addition to research on control of specific pollutants such as sulfur oxides and nitrogen oxides, NCAPC has initiated programs aimed at control of pollutants from a broad spectrum of industries and for the improvement of equipment that is generally applicable to pollutant removal. The smelter industry studies and fabric filters development, previously mentioned, are examples of these activities. In carrying out these studies, the systems engineering approach will be used to develop the needed programs which will then be conducted cooperatively with industrial groups. In this regard it is important that such studies be joint efforts to keep responsive to the needs of industry groups expected to utilize the processes and equipment developed.

In the future, work will also continue on the multiple pollution problems of solid waste disposal. Contract work already under way is directed towards control 
of air pollution created during municipal refuse disposal, since this constitutes a problem of concern at the present time. Control involves both improvement of incinerator designs and the application of better control devices. As with other programs, a series of systems studies will be launched by the National Center to define the over-all problem of air pollution from waste disposal and the research and development needed to control the problem. These systems studies are expected to result in a sizable contract program based on a modest effort of in-house research and development by the Center itself over the last nine years.

\section{II}

\section{The Control of Pollution from Vehicles}

Automobile manufacturers have been successful in meeting federal standards for reduction of hydrocarbon and carbon monoxide emissions required nationally for the 1968 model-year cars. ${ }^{11}$ To meet the proposed standards for hydrocarbons and carbon monoxide for 1970 model-year cars, the motor vehicle industry will further optimize the two basic approaches utilized for Ig68 model-year vehicles. The first involves, for the most part, injection of air into the exhaust manifold at the point of hettest exhaust gas temperature close to the exhaust valves in order to continue the combustion of the pollutants in the exhaust system. The second approach utilizes modifications in the engine induction and ignition systems.

Although these control techniques are resulting in considerable progress, the growth in vehicle population across the nation indicates that a further reduction of pollutant emission levels may be necessary. Systems studies to further define this need are now under way. At present, technology to achieve still lower emission levels has not been reduced to practice, although several promising systems are under intensive research and development, particularly by industry. One such system involves a high-temperature reactor to replace the exhaust manifold in the present engine configuration. The major problem today involves the development of alloys capable of resisting the high temperatures involved over the life of the vehicle and at a reasonable cost. The federal program in control device development is aimed towards assisting the automobile industry in such development and towards control of additional pollutants (such as niurogen oxides and particulates) that are not specified for control at the present time. The NCAPC is also participating in cooperative research programs, jointly funded by the federal government and the Coordinating Research Council, an industry group jointly supported by the Automobile Manufacturers Association and the American Petroleum Institute. These studies are oriented toward further definition of the pollution problem from motor vehicles-involving either the automotive engine or the fuels used.

As previously mentioned, control of nitrogen oxide emissions is not yet required

\footnotetext{
${ }^{11}$ These standards are set forth in 45 C.F.R. $\$ \$ 85.1-.87$ (I967). Proposed standards for I970 modelyear cars have been issued. 33 Fed. Reg. 8304 (I968).
} 
by federal standards. However, considerable attention is being given by both industry and government to means by which nitrogen oxide emissions might be controlled without sacrifice to the control of hydrocarbon and carbon monoxide emissions.

One system, which has received rather wide attention in both university and industry research circles, involves the recirculation of a controlled amount of the total exhaust gas back through the engine intake system. By diluting the combustible mixture charge admitted to the engine cylinders, the peak temperatures are reduced-resulting in reduced formation of nitrogen oxides-though at some loss in engine performance.

While reduction in emissions will probably be met during the next decade by improving conventional reciprocating engines, serious attention will also be given to possible new approaches involving unconventional vehicle propulsion systems having inherently low emission characteristics. NCAPC is currently supporting systems studies defining the state-of-the-art of technology relating to electrically propelled vehicles (Arthur D. Little) and other types of unconventional combustion systems for vehicle propulsion (Battelle Memorial Institute).

Power systems such as turbines and steam engines are under study by a number of groups. Using updated technology, researchers have recently built vehicles powered by steam. Hydrocarbon and carbon monoxide levels discharged by these vehicles are quite low. These modern steam cars appear to have overcome many of the drawbacks of early "Stanley Steamer" type vehicles which were slow to warm up, consumed large amounts of water, and sometimes exploded. However, much remains to be done before comparable performance and economies of the present gasolinepowered vehicles are realized.

For the more distant future, the electric vehicle appears to offer considerable potential. Even now, electrically propelled vehicles using batteries are practical for limited application. Further advancement of battery or fuel-cell technology will, however, be required before an electric-powered family car of acceptable performance will become economically attractive.

\section{III}

\section{Air Pollution Instrumentation}

Efficient, accurate, and easy-to-use instrumentation for measuring pollutants in the ambient air and in stacks and exhausts is vital to any air pollution control program. The complexity of instrumental requirements and the need for instrumentation to determine the quality and quantity of air pollutant emissions from stationary sources varies significantly, depending on the nature of the pollutant and the location of the measurement (within the stack, at the mouth of the stack, or in the plume downwind from the stack). 
In-stack instrumentation is already available for measuring inorganic, gaseous emissions such as carbon dioxide, nitrogen oxides, and sulfur oxides resulting from fossil fuel combustion. But before the gas from a stack can be sampled, expensive scaffolding and a platform must be built on the stack and probe holes provided. Sampling then involves measuring the rate of flow of gas through the stack and extracting a sample of stack gas to be analyzed for the concentration of various pollutants.

It would be much more convenient to measure stack emissions from a distance. Through contracts the NCAPC has under development such instrumentation. A sulfur dioxide monitor utilizing infra-red technology to measure radiation from hot gases emitted from stacks has already been built by a contractor and is now being evaluated by the NCAPC. The Edison Electric Institute and NCAPC are jointly supporting the development of a remote monitor employing a laser system for measuring light transmission through stack plumes. Such measurement is related to the visual effects of particulates in the plume.

Compact, portable instruments that can be airborne are needed to sample the quality of air at different levels in the atmosphere and to measure dispersal of pollutants from plumes. Although such an instrument is already commercially available for sulfur oxides, similar instruments do not exist for nitrogen oxides and other pollutants. There is also a need for improved instruments for the NCAPC's nationwide Continuous Air Monitoring Network. The current array of instruments is essentially the same package adopted ten years ago. During the next several years it is expected that simplified and improved instruments will be developed which will constitute a significant improvement over existing instrumentation and will extend our abilities to pollutants not currently being measured.

Instrumentation for measuring vehicular emissions is generally adequate for testing vehicles in a well-equipped laboratory. If all vehicles are to be inspected at regular intervals during their use, however, instrumentation must be developed that will make testing simpler and less costly.

\section{IV}

\section{METEOROLOGY}

Because atmospheric properties control the transport and dispersal of pollutants, they are intimately associated with the concentration levels of pollutants discharged into the atmosphere from various sources. Hence, a meteorology program is an essential input to a program for the control of atmospheric pollution. The NCAPC has utilized meteorology in its program since its inception in 1955.

Several urban diffusion models-mathematical models relating pollutant sources to atmospheric concentrations through mathematical simulation of meteorological processes-have been developed and applied to a variety of air pollution problems 
ranging from the interpretation of air quality data to experimental programs for forecasting pollutant concentrations within urban areas.

The culmination of meteorological research in air pollution is to provide air pollution control officials with a logical basis for initiating control measures to maintain air quality standards. The Air Pollution Potential Forecast Program was begun in 1960 and since that time ninety-two episodes of high air pollution potential have been forecast; many of these episodes were related to severe local pollution conditions. In July 1967 , the routine operation of the Air Pollution Potential Forecast Program, developed by the NCAPC, was transferred to the Weather Bureau for machine operation. The responsibility for research and continued development of the program remains, however, with the NCAPC, and improved forecasting techniques are now being developed. Plans are now being implemented to produce and test quantitative forecasts, forecasts that indicate the relative dilution capacity of the atmosphere over the country.

\section{Conclusion}

In the area of control of pollution from stationary sources, major research and development is now concentrated on the control of sulfur oxides. In the future there will be expanded programs for other pollutants, especially nitrogen oxides.

Major emphasis on control of emissions from motor vehicles is now focused on reduction of carbon monoxide and hydrocarbons. Future efforts will focus on control of nitrogen oxides and particulates and on unconventional vehicles with low pollution potential, such as electric-powered and steam-powered cars.

Instruments and techniques are now available for measuring many pollutants, especially inorganic gases, but there is a need for automated, smaller-sized instruments both for stationary sampling stations and for airborne sampling of the atmosphere. There is also a need for remote-type monitors capable of measuring stack emissions from a distance.

In the area of meteorology, a number of urban diffusion models and an air pollution potential forecast program are now operational; improved models and quantitative forecasting methods are under development. 